\title{
LA CREACIÓN DE DINERO EN LA ECONOMÍA MODERNA
}

\author{
Michael McLeay \\ Amar Radia \\ Ryland Thomas*
}

H ste artículo explica cómo se crea la mayor parte del dinero en la economía moderna mediante préstamos de la banca comercial. La creación de dinero en la práctica difiere de algunas concepciones populares erróneas; los bancos no actúan simplemente como intermediarios, prestando los depósitos que los ahorradores colocan en ellos, y tampoco "multiplican" el dinero del banco central para crear depósitos y préstamos nuevos.

La cantidad de dinero creada en la economía depende en últimas de la política monetaria del banco central. En tiempos normales, esto se lleva a cabo fijando tasas de interés. El banco central también puede afectar directamente la cantidad de dinero mediante la compra de activos o "flexibilización cuantitativa".

\section{Visión general}

En la economía moderna, la mayor parte del dinero toma la forma de depósitos bancarios. Pero a menudo no se entiende cómo se crean esos depósitos: la principal manera de crearlos son los préstamos que hacen los bancos comerciales. Cada vez que un banco hace un préstamo, crea simultáneamente un depósito correspondiente en la cuenta bancaria del prestatario, con lo cual crea dinero nuevo.

* Los autores son miembros del Directorio de Análisis Monetario del Banco de Inglaterra y agradecen a Lewis Kirkham por su ayuda en la elaboración de este artículo. Tomado de Bank of England Quarterly Bulletin, 2014, primer trimestre, [http://www.bankofengland.co.uk/publications/Documents/quarterlybulletin/2014/ qb14q1prereleasemoneycreation.pdf]. Traducción de Alberto Supelano; no fue elaborada por el Banco de Inglaterra y no es una traducción oficial del Banco, el cual no se hace responsable de ningún error contenido en ella. Se publica con las autorizaciones correspondientes. Fecha de recepción: 30 de julio de 2015, fecha de aceptación: 29 de octubre de 2015. Sugerencia de citación: McLeay, M.; A. Radia y R. Thomas. "La creación de dinero en la economía moderna", Revista de Economía Institucional 17, 33, 2015, pp. 355-383. DOI: http://dx.doi. org/10.18601/01245996.v17n33.16 
E1 modo real de crear hoy el dinero difiere de la descripción que se encuentra en algunos manuales de economía:

- En vez de que los bancos reciban depósitos cuando los hogares ahorran y luego los presten, los préstamos bancarios crean depósitos.

- En tiempos normales, el banco central no fija la cantidad de dinero en circulación, ni el dinero del banco central es "multiplicado" en más préstamos y depósitos.

Aunque los bancos comerciales crean dinero haciendo préstamos, no pueden crearlo gratuitamente y sin límites. La cantidad que los bancos pueden prestar es limitada si quieren seguir siendo rentables en un sistema bancario competitivo. La regulación prudencial también actúa como una restricción a las actividades bancarias para mantener la resiliencia del sistema financiero. Y los hogares y compañías que reciben el dinero creado por los préstamos nuevos pueden realizar acciones que afecten la cantidad de dinero; por ejemplo, "destruir" dinero rápidamente usándolo para pagar sus deudas vigentes.

La política monetaria opera como límite último a la creación de dinero. El Banco de Inglaterra intenta asegurar que el volumen de creación de dinero en la economía sea consistente con una inflación baja y estable. En tiempos normales, el Banco de Inglaterra implementa la política monetaria fijando la tasa de interés de las reservas que se mantienen en el banco central. Esta luego influye en una variedad de tasas de interés de la economía, incluidas las tasas de los préstamos bancarios.

En circunstancias excepcionales, cuando las tasas de interés están en su límite efectivo inferior, la creación de dinero y el gasto en la economía aún pueden ser muy bajos para ser consistentes con los objetivos de política monetaria del banco central. Una respuesta posible es emprender una serie de compras de activos o "flexibilización cuantitativa" (FC). La FC pretende elevar directamente la cantidad de dinero en la economía comprando activos, principalmente de las compañías financieras no bancarias.

La FC inicialmente aumenta la cantidad de depósitos bancarios que mantienen esas compañías (en vez de los activos que venden). Esas compañías entonces querrán volver a balancear sus portafolios de activos comprando activos de mayor rendimiento, lo que eleva el precio de esos activos y estimula el gasto en la economía.

Como subproducto de la FC se crean nuevas reservas de los bancos comerciales en el banco central. Pero estas no son una parte importante del mecanismo de transmisión. Este artículo explica por qué, en tiempos normales, estas reservas no se pueden multiplicar en más préstamos y depósitos y por qué no son "dinero gratuito" para los bancos.

“E1 dinero en la economía moderna: una introducción”, el escrito que acompaña a este artículo, da una visión general de lo que se entiende por dinero y de los diferentes tipos de dinero que existen en una economía moderna, aludiendo brevemente a la manera de crear cada tipo de dinero. Este artículo explora la creación de dinero en la economía moderna en más detalle.

Empieza describiendo dos concepciones erróneas comunes acerca de la creación de dinero, y explica por qué, en la economía moderna, 
el dinero es en su mayoría creado por los bancos comerciales haciendo préstamos ${ }^{1}$. Luego discute los límites de la capacidad del sistema bancario para crear dinero y el importante papel de las políticas del banco central para asegurar que el crecimiento del crédito y del dinero sea consistente con la estabilidad monetaria y financiera de la economía. La sección final discute el papel del dinero en el mecanismo de transmisión monetaria durante periodos de flexibilización cuantitativa (FC), y disipa algunos mitos que rodean a la creación de dinero y la $\mathrm{FC}^{2}$.

\section{DOS CONCEPCIONES ERRÓNEAS ACERCA DE LA CREACIÓN DE DINERO}

La inmensa mayoría del dinero en manos del público toma la forma de depósitos bancarios. Pero a menudo no se entiende de dónde proviene el volumen de depósitos bancarios. Una concepción errónea común es que los bancos actúan simplemente como intermediarios, prestando los depósitos que los ahorradores colocan con ellos. Según esta concepción los depósitos normalmente son creados por la decisión de ahorrar de los hogares y los bancos luego prestan los depósitos existentes a los prestatarios, por ejemplo, a las empresas que buscan financiar inversiones o a los individuos que quieren comprar viviendas.

En realidad, cuando los hogares eligen ahorrar más dinero en cuentas bancarias, esos depósitos llegan simplemente a costa de depósitos que de otro modo habrían ido a las empresas en pago de bienes y servicios. El ahorro en sí mismo no aumenta los depósitos o "fondos disponibles" para que los bancos presten. De hecho, ver a los bancos apenas como intermediarios ignora que, en la realidad de la economía moderna, los bancos comerciales son los creadores de dinero de depósito. Este artículo explica por qué en vez de que los bancos presten depósitos que se colocan en ellos, el acto de prestar crea depósitos; al contrario de la secuencia que se suele describir en los manuales ${ }^{3}$.

Otra concepción errónea común es que el banco central determina la cantidad de préstamos y depósitos controlando la cantidad de dinero del banco central; el enfoque del "multiplicador monetario". Según esta concepción, los bancos centrales implementan la política monetaria eligiendo una cantidad de reservas. Y, debido a que se supone una relación constante entre dinero en sentido amplio y base monetaria, estas reservas se "multiplican"

${ }^{1}$ En este artículo se usan los términos "bancos" y "bancos comerciales" para referirse a los bancos y sociedades de construcción en conjunto.

${ }^{2}$ Un corto video explica algunos temas esenciales de este artículo, [www.youtube.com/watch?v=CvRAqR2pAgw].

${ }^{3}$ Una extensa literatura reconoce la naturaleza "endógena" de la creación de dinero en la práctica; ver, p. ej., Moore (1988), Howells (1995) y Palley (1996). 
produciendo una variación mucho mayor de préstamos y depósitos bancarios. Para que la teoría se sostenga, el monto de reservas debe ser una restricción obligatoria a la concesión de préstamos, y el banco central debe determinar directamente la cantidad de reservas. Aunque la teoría del multiplicador monetario puede ser una manera útil de presentar el dinero y la banca en los manuales, no es una descripción exacta de cómo se crea el dinero en realidad. En vez de controlar la cantidad de reservas, los bancos centrales hoy normalmente implementan la política monetaria fijando el precio de las reservas, es decir, las tasas de interés.

En realidad, ni las reservas son una restricción obligatoria a la concesión de préstamos ni el banco central fija el monto de reservas que están disponibles. Igual que la relación entre depósitos y préstamos, la relación entre reservas y préstamos normalmente funciona al contrario de como describen algunos manuales. Los bancos primero deciden cuánto prestan dependiendo de las oportunidades de colocación rentable de crédito a su disposición, las cuales dependen crucialmente de la tasa de interés que fija el Banco de Inglaterra. Estas decisiones de préstamo son las que deciden cuántos depósitos bancarios crea el sistema bancario. A su vez la cantidad de depósitos bancarios influye en la cantidad de dinero del banco central que los bancos quieren mantener en reservas (para satisfacer retiros del público, hacer pagos a otros bancos o cumplir los requerimientos de liquidez regulatorios), la cual, en tiempos normales, luego es suministrada a demanda por el Banco de Inglaterra. El resto de este artículo analiza estas prácticas en más detalle.

\section{LA CREACIÓN DE DINERO EN LA REALIDAD}

El CRÉdito CREA dePósitos - DETERMINACión DEL DiNERO EN SENTIDO AMPLio A Nivel Agregado

Como se explica en "El dinero en la economía moderna: una introducción”, el dinero en sentido amplio es una medida de la cantidad total de dinero que mantienen los hogares y las compañías. El dinero en sentido amplio está formado por depósitos bancarios -que en esencia son pagarés de los bancos comerciales a los hogares y compañías- y efectivo en circulación -en su mayor parte pagarés del banco central-4,5. De los dos tipos de dinero en sentido amplio, los

\footnotetext{
${ }^{4}$ La definición de dinero en sentido amplio que usa el Banco de Inglaterra, M4 ${ }^{\text {ex }}$, incluye una gama de obligaciones del banco más amplia que los depósitos regulares; para más detalles, ver Burgess y Janssen (2007). Por simplicidad, este artículo describe todas esas obligaciones como depósitos. E1 recuadro posterior da detalles del conjunto de agregados monetarios populares en el Reino Unido.

${ }^{5}$ Cerca del $6 \%$ del dinero en circulación está constituido por monedas, que se producen en la Casa de Acuñación Real. De los billetes que circulan en la
} 
depósitos bancarios son la vasta mayoría: el 97\% del actual volumen en circulación ${ }^{6}$. Y en la economía moderna, la mayoría de esos depósitos bancarios es creada por los mismos bancos comerciales.

Los bancos comerciales crean dinero, en forma de depósitos bancarios, haciendo préstamos nuevos. Cuando un banco hace un préstamo, por ejemplo, a alguien que firma una hipoteca para comprar una casa, normalmente no lo hace dándole miles de libras en billetes. En vez de ello, acredita en su cuenta bancaria un depósito bancario por el monto de la hipoteca. En ese momento se crea dinero nuevo. Por esta razón, algunos economistas se refieren a los depósitos bancarios como "dinero de estilógrafo", creado por los trazos de los estilógrafos de los banqueros cuando aprueban préstamos ${ }^{7}$.

Este proceso se ilustra en la gráfica 1, que muestra la manera en que los nuevos préstamos afectan los balances de diferentes sectores de la economía (en "El dinero en la economía moderna: una introducción" se presentan diagramas de balance similares). Como se muestra en la tercera fila, los nuevos depósitos aumentan los activos de los consumidores (que aquí representan a los hogares y las compañías) -las barras punteadas [negras] adicionales-y el préstamo nuevo aumenta sus obligaciones -las barras blancas adicionales-. Se ha creado nuevo dinero en sentido amplio. De manera similar, ambos lados del balance de la banca comercial aumentan cuando se crean dinero y préstamos nuevos. Es importante señalar que aunque el diagrama simplificado de la gráfica 1 muestre que la cantidad de dinero nuevo creado es idéntica al volumen de préstamos nuevos, en la práctica habrá diversos factores que luego pueden ocasionar que la cantidad de depósitos sea diferente del volumen de préstamos. Estos se discuten en detalle en la siguiente sección.

Mientras que en el balance de los consumidores se ha creado nuevo dinero en sentido amplio, la primera fila de la gráfica 1 muestra que esto sucede sin que cambie la cantidad de dinero del banco central o "base monetaria", al menos en principio. Como ya se discutió, el mayor volumen de depósitos puede significar que los bancos desean o están obligados a mantener más dinero del banco central para satisfacer retiros del público o hacer pagos a otros bancos. Y, en tiempos normales, las reservas son suministradas "a demanda" por el Banco

economía del Reino Unido, algunos son emitidos por ciertos bancos comerciales de Escocia e Irlanda del Norte.

${ }^{6}$ En diciembre de 2013.

7 El dinero de estilógrafo se analiza en Tobin (1963), quien lo menciona en el contexto de una argumentación referente a que en la práctica los bancos no pueden crear cantidades ilimitadas de dinero. 
de Inglaterra a los bancos comerciales a cambio de otros activos de sus balances. La cantidad agregada de reservas de ningún modo restringe directamente el monto de préstamos bancarios ni la creación de depósitos.

\section{Gráfica 1}

Creación de dinero por el sector bancario agregado haciendo préstamos adicionales $^{(a)}$
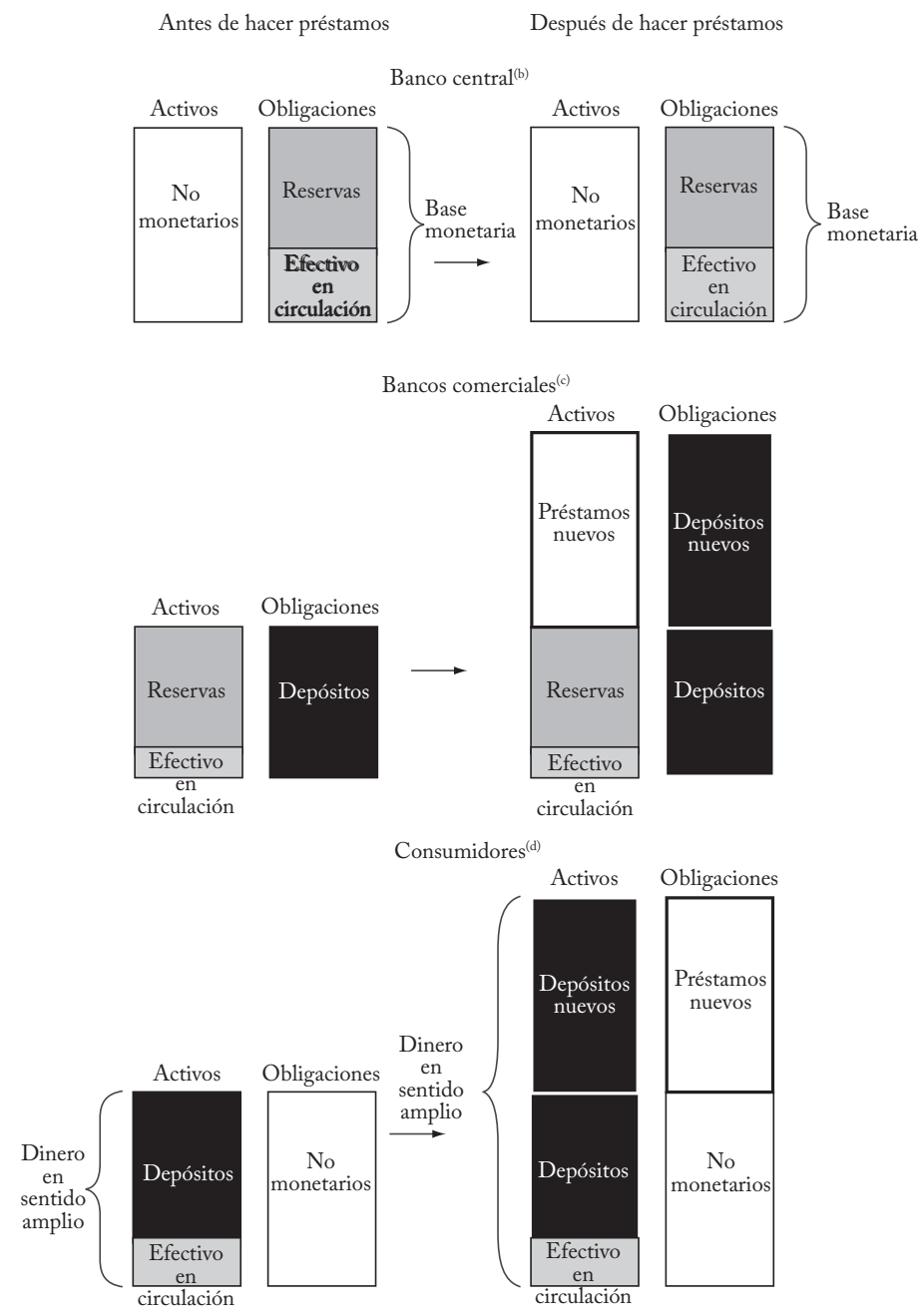

(a) Los balances son muy estilizados para facilitar la exposición: las cantidades de cada tipo de dinero que se muestran no corresponden a las cantidades que realmente se mantienen en el balance de cada sector.

(b) El balance del banco central solo muestra las obligaciones y activos correspondientes de la base monetaria. En la práctica, el banco central mantiene otras obligaciones no monetarias. Sus 
activos no monetarios son en su mayoría deuda del gobierno. Aunque la deuda del gobierno es en realidad mantenida por el Fondo de Compra de Activos del Banco de Inglaterra, de modo que no aparece directamente en el balance.

(c) Los balances de los bancos comerciales solo muestran los activos y las obligaciones antes de hacer préstamos.

(d) Los consumidores representan el sector privado de hogares y empresas. El balance solo muestra los activos de dinero en sentido amplio y las obligaciones correspondientes. Las obligaciones no monetarias de los consumidores incluyen préstamos asegurados y no asegurados existentes.

Esta descripción de la creación de dinero contrasta con la noción de que los bancos solo pueden prestar dinero preexistente, mencionada en la sección anterior. Los depósitos bancarios son simplemente un registro de cuánto les debe el banco a sus clientes. De modo que son una obligación del banco y no un activo que puedan prestar. Una concepción errónea relacionada es que los bancos pueden prestar sus reservas. Las reservas solo se pueden prestar entre bancos, puesto que los consumidores no tienen acceso a las cuentas de reservas en el Banco de Inglaterra ${ }^{8}$.

\section{OTRAS MANERAS DE CREAR Y DESTRUIR DEPÓSITOS}

Así como tomar un préstamo nuevo crea dinero, el pago de préstamos bancarios destruye dinero 9 . Por ejemplo, supongamos que un consumidor ha gastado dinero en el supermercado durante el mes usando una tarjeta de crédito. Cada compra que ha hecho usando la tarjeta de crédito habrá aumentado los préstamos pendientes en el balance del consumidor y los depósitos en el balance del supermercado (en forma similar a la que se muestra en la gráfica 1 ). Si el consumidor pagara totalmente la factura de su tarjeta de crédito al final del mes, su banco reduciría la cantidad de depósitos en la cuenta del consumidor por el valor de esa factura, destruyendo así todo el dinero recién creado.

Los préstamos que hacen los bancos y los reembolsos de los consumidores son las maneras más significativas de crear y destruir depósitos bancarios en la economía moderna. Pero están lejos de ser las únicas. La creación o destrucción de depósitos también ocurrirá cada vez que el sector bancario (incluido el banco central) compre o

8 Parte de la confusión puede provenir del uso del término "reservas" entre algunos economistas cuando se refieren al "exceso de reservas": mantener saldos superiores a los que exigen los requerimientos de reservas regulatorios. En este contexto, "prestar reservas" puede ser una forma abreviada de describir el proceso de aumento de préstamos y depósitos hasta que el banco alcanza su relación máxima. Como no hay requerimientos de reservas en el Reino Unido, ese proceso es menos relevante para los bancos del Reino Unido.

9 La caída del crédito bancario en el Reino Unido desde 2008 es una razón importante para que el crecimiento del dinero en la economía haya sido mucho menor que en los años anteriores a la crisis, como se discute en Bridges et al. (2011) y Butt et al. (2012). 
venda activos existentes de o a los consumidores, o, más a menudo, de las empresas o el gobierno.

La compra y venta de bonos del gobierno por los bancos es una manera particularmente importante por la cual la compra o venta de activos existentes por los bancos crea y destruye dinero. Los bancos suelen comprar y mantener bonos del gobierno como parte del portafolio de activos líquidos que pueden vender rápidamente por dinero del banco central, por ejemplo, cuando los depositantes quieren retirar efectivo en grandes cantidades ${ }^{10}$. Cuando los bancos compran bonos del gobierno al sector público no bancario acreditan depósitos bancarios a los vendedores ${ }^{11}$. Y, como se comentó antes, las compras de activos del banco central, conocidas como flexibilización cuantitativa (FC), tienen implicaciones similares para la creación de dinero.

El dinero también se puede destruir mediante la emisión de instrumentos de deuda y de capital de largo plazo por los bancos. Además de los depósitos, los bancos mantienen otras obligaciones en sus balances. Los bancos manejan sus obligaciones para asegurar que tengan al menos algunas obligaciones de capital y de deuda de largo plazo para atenuar ciertos riesgos y cumplir las exigencias regulatorias. Debido a que estas obligaciones que "no constituyen depósitos" representan inversiones de largo plazo de los hogares y compañías en el sistema bancario, no se pueden cambiar por efectivo tan fácilmente como los depósitos bancarios y, por tanto, pueden aumentar la resiliencia del banco. Cuando los bancos emiten esos instrumentos de capital y de deuda de largo plazo a compañías financieras no bancarias, esas compañías les pagan por ellos con depósitos bancarios. Eso reduce la cantidad de obligaciones de depósitos, o dinero, en el balance del sector bancario e incrementa sus obligaciones que no constituyen depósitos ${ }^{12}$.

La compra y venta de activos existentes y la emisión de obligaciones de largo plazo pueden generar una brecha entre crédito y depósitos en una economía cerrada. Además, en una economía abierta como

\footnotetext{
${ }^{10}$ Por esta razón las tenencias de algunos bonos del gobierno se cuentan para el cumplimiento de los requerimientos prudenciales de liquidez, como describen en más detalle Farag et al. (2013).

${ }^{11}$ En el diagrama de un balance como el de la gráfica 1, una compra de bonos del gobierno a los consumidores por parte de los bancos estaría representada por un cambio en la composición de activos de los consumidores de bonos del gobierno a depósitos y un aumento de depósitos y bonos del gobierno en el balance de los bancos comerciales.

${ }^{12}$ Las compras de bonos del gobierno por los bancos comerciales y su emisión de deuda de largo plazo y capital tuvieron gran influencia en el crecimiento del dinero en sentido amplio durante la crisis financiera, como se discute en Bridges et al. (2011) y Butt et al. (2012).
} 
el Reino Unido, los depósitos pueden pasar de residentes en el país a residentes en el extranjero, o los depósitos en libras esterlinas se pueden convertir en depósitos en moneda extranjera. Estas transacciones no destruyen dinero per se, pero los depósitos de residentes en el extranjero y los depósitos en moneda extranjera no siempre se cuentan como parte de la oferta monetaria de un país.

\section{LÍMITES A LA CREACIÓN DE DINERO EN SENTIDO AMPLIO}

Aunque los bancos comerciales crean dinero a través de su comportamiento crediticio, en la práctica no pueden hacerlo sin límites. En particular, el precio de los préstamos -es decir, la tasa de interés (más comisiones) que cobran los bancos- determina la cantidad en que los hogares y las compañías desearán endeudarse. Diversos factores influyen en el precio de los préstamos nuevos, en particular la política monetaria del Banco de Inglaterra, que afecta el nivel de diversas tasas de interés de la economía.

Los límites a la creación de dinero por el sistema bancario se analizaron en un artículo de James Tobin, quien obtuvo el Premio Nobel, y este tema ha sido objeto de debate reciente entre numerosos analistas y blogueros económicos ${ }^{13}$. En la economía moderna hay tres conjuntos principales de restricciones que limitan la cantidad de dinero que pueden crear los bancos.

1. Los bancos enfrentan limites a la cantidad que pueden prestar. En particular:

- Las fuerzas del mercado restringen el crédito porque los bancos individuales tienen que poder prestar de modo rentable en un mercado competitivo.

- El crédito también está limitado porque los bancos tienen que tomar medidas para atenuar los riesgos asociados al otorgamiento de préstamos adicionales.

- La política regulatoria actúa como una restricción a las actividades bancarias para atenuar la acumulación de riesgos que pueden amenazar la estabilidad del sistema financiero.

2. La creación de dinero también es limitada por el comportamiento de los tenedores de dinero: hogares y empresas. Los hogares y empresas que reciben el dinero recién creado pueden responder realizando tran-

13 Tobin (1963) argumentó que los bancos no poseen un "jarro de la viuda", aludiendo a una historia bíblica (primero referenciada en economía por John Maynard Keynes) en la que una viuda puede llenar milagrosamente un jarro de aceite durante una hambruna. Tobin argumentó que había límites a la cantidad de préstamos que podían corresponder automáticamente a depósitos. 
sacciones que lo destruyen inmediatamente, por ejemplo, pagando préstamos pendientes.

3. La última restricción a la creación de dinero es la politica monetaria. Influyendo en el nivel de tasas de interés de la economía, la política monetaria del Banco de Inglaterra afecta la cantidad en que los hogares y compañías desean endeudarse. Esto ocurre directamente a través de la influencia en las tasas de los préstamos que cobran los bancos, y también indirectamente a través del efecto general de la política monetaria en la actividad económica. Por ello, el Banco de Inglaterra puede asegurar que el crecimiento del dinero es coherente con su objetivo de inflación baja y estable.

El resto de esta sección explica cómo funciona en la práctica cada uno de estos mecanismos.

\section{Límites A LA CANTIDAd QUE PUEDEN PRESTAR LOS BANCOS}

\section{Las fuerzas del mercado que enfrentan los bancos individuales}

La gráfica 1 mostró que, para el sector bancario agregado, los préstamos son creados inicialmente con depósitos correspondientes. Pero eso no significa que un banco individual dado pueda prestar gratuitamente y crear dinero sin límites. Esto se debe a que los bancos tienen que poder prestar de modo rentable en un mercado competitivo, y asegurar que manejan adecuadamente los riesgos asociados a la concesión de préstamos.

Los bancos reciben pagos de intereses sobre sus activos, como los préstamos, pero en general también deben pagar intereses sobre sus obligaciones, como las cuentas de ahorros. El modelo de negocios de un banco depende de que reciba una tasa de interés sobre los préstamos ( $u$ otros activos) mayor que la tasa que paga sobre sus depósitos (u otras obligaciones). Las tasas de interés sobre los activos y obligaciones de los bancos dependen de la tasa fijada por el Banco de Inglaterra, que actúa como restricción última a la creación de dinero. El banco comercial usa la diferencia, o margen, entre el rendimiento esperado de sus activos y obligaciones para cubrir sus costos operativos y obtener ganancias ${ }^{14}$. Para hacer préstamos adicionales, un banco individual normalmente tendrá que reducir sus tasas de crédito respecto de sus competidores para inducir a que los hogares y compañías pidan más préstamos. Y una vez que ha hecho el préstamo bien puede "perder" los depósitos que ha creado con los bancos competidores. Ambos

\footnotetext{
${ }^{14}$ Para una explicación de cómo fijan los bancos los precios de los préstamos nuevos, ver Button et al. (2010).
}

Revista de Economía Institucional, vol. i7, N. ${ }^{\circ} 33$, Segundo Semestre/2oi 5, Pp. 355-383 
factores afectan la rentabilidad para el banco individual de hacer un préstamo e influyen en la cantidad de préstamos que concede.

Por ejemplo, supongamos que un banco dado reduce la tasa que cobra por sus préstamos y atrae a un hogar para que tome una hipoteca para comprar una casa. En el momento en que se hace el préstamo hipotecario se acreditan depósitos nuevos en la cuenta del hogar. Y una vez este compra la casa, pasa sus depósitos nuevos al vendedor de la casa. Esta situación se muestra en la primera fila de la gráfica 2. El comprador queda con un activo nuevo en forma de una casa y una obligación nueva en forma de un préstamo nuevo. El vendedor queda con dinero en forma de depósitos bancarios en vez de una casa. Es muy probable que la cuenta del vendedor sea de un banco diferente al del comprador. De modo que cuando la transacción se lleve a cabo, los depósitos nuevos se transferirán al banco del vendedor, como se muestra en la segunda fila de la gráfica 2. E1 banco del comprador tendría entonces menos depósitos que activos. En primer lugar, el banco del comprador se arregla con el banco del vendedor transfiriendo reservas. Pero eso dejaría al banco del comprador con menos reservas y más préstamos en relación con sus depósitos que antes. Es posible que esto sea problemático para el banco porque aumentaría el riesgo de que no pueda satisfacer todos sus posibles desembolsos. Y, en la práctica, los bancos hacen cada día muchos de esos préstamos. De modo que si un banco dado financiara todos sus préstamos nuevos de esta manera, pronto se quedaría sin reservas.

Por ello, los bancos intentan atraer o retener pasivos adicionales que acompañen a sus préstamos nuevos. En la práctica otros bancos también están haciendo préstamos nuevos y creando depósitos nuevos, por lo que una manera de hacerlo es tratar de atraer algunos de esos depósitos recién creados. En un sector bancario competitivo, eso puede implicar un aumento de la tasa que ofrecen a los hogares sobre sus cuentas de ahorros. Atrayendo depósitos nuevos, el banco puede aumentar sus préstamos sin quedarse sin reservas, como se muestra en la tercera fila de la gráfica 2. En forma alternativa, un banco puede pedir prestado a otros bancos o atraer otros tipos de pasivos, al menos temporalmente. Pero, bien sea a través de depósitos u otros pasivos, el banco necesita asegurar que atrae y retiene algunos tipos de fondos para seguir ampliando el crédito. Y el costo de esa necesidad se debe comparar con el interés que el banco espera obtener sobre los préstamos que está haciendo, el cual depende a su vez del nivel de la tasa bancaria fijada por el Banco de Inglaterra. Por ejemplo, si un banco sigue atrayendo nuevos prestatarios y aumentando el crédito reduciendo las tasas 
hipotecarias, e intenta atraer nuevos depósitos aumentando las tasas que paga sobre los depósitos de sus clientes, pronto podría encontrar que no es rentable seguir ampliando sus préstamos. La competencia por préstamos y depósitos, y el deseo de obtener ganancias limitan, por tanto, la creación de dinero por los bancos.

\section{Manejo de los riesgos asociados a la concesión de préstamos}

Los bancos también deben manejar los riesgos asociados a la concesión de préstamos nuevos. Una manera de hacerlo es asegurar que atraen depósitos relativamente estables para compensar sus préstamos nuevos, es decir, depósitos con poca o ninguna probabilidad de que sean retirados en grandes cantidades. Esto puede actuar como un límite adicional a la cantidad que los bancos pueden prestar. Por ejemplo, si todos los depósitos que mantiene un banco estuvieran en forma de cuentas de acceso instantáneo, como las cuentas corrientes, el banco podría correr el riesgo de que muchos de esos depósitos sean retirados en un corto periodo de tiempo. Debido a que los bancos tienden a prestar por periodos de muchos meses o años, el banco podría no ser capaz de reembolsar todos esos depósitos; y enfrentaría una gran de riesgo de liquidez. Para reducir el riesgo de liquidez, los bancos intentan asegurar que algunos de sus depósitos sean fijos por cierto periodo de tiempo, o plazo ${ }^{15}$. Sin embargo, es probable que los consumidores exijan compensación por la inconveniencia de mantener depósitos de largo plazo, y es probable que estos sean más costosos para los bancos, lo que limita la cantidad de préstamos que los bancos desean hacer. Y como ya se comentó, si los bancos se protegen contra el riesgo de liquidez emitiendo obligaciones de largo plazo, esto puede destruir dinero directamente cuando las empresas pagan por ellos usando depósitos.

Los préstamos de los bancos individuales también son limitados por consideraciones de riesgo de crédito. Este es el riesgo para el banco de dar crédito a prestatarios que resultan ser incapaces de pagar sus préstamos. En parte, los bancos pueden protegerse contra el riesgo de crédito teniendo capital suficiente para absorber algunas pérdidas inesperadas sobre sus préstamos. Pero como los préstamos siempre implican algún riesgo de que los bancos incurran en pérdidas, el costo de estas pérdidas se tendrá en cuenta cuando fijan el precio de los

${ }^{15}$ Los bancos también se protegen contra el riesgo de liquidez manteniendo activos líquidos (incluidas reservas y efectivo), que se pueden usar directamente para cubrir desembolsos, o convertir rápidamente y a bajo costo en los activos que puedan. Aunque si los bancos compran activos líquidos como bonos del gobierno a entidades no bancarias, esto podría crear más depósitos. 
Gráfica 2

Creación de dinero por un banco individual que hace un préstamo adicional ${ }^{(\mathrm{a})}$

\begin{tabular}{l} 
Cambios en los balances del comprador y el vendedor de la \\
Comprador de la casa \\
Activos Obligaciones \\
\cline { 3 - 3 }
\end{tabular}

Cambios en los balances del comprador de la casa y los bancos del vendedor

Banco del comprador Banco del vendedor Banco del comprador Banco del vendedor

Activos Obligaciones Activos Obligaciones Activos Obligaciones Activos Obligaciones

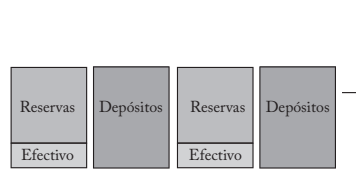

Balances antes de hacerse el préstamo

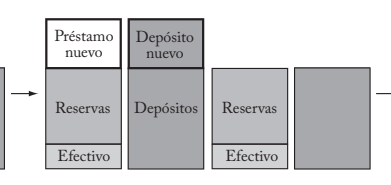

El prestador de la hipoteca crea nuevos depósitos..

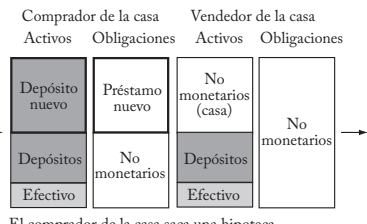

$$
\rightarrow \text { De }
$$

Comprador de la casa Vendedor de la casa

Activos Obligaciones Activos Obligaciones

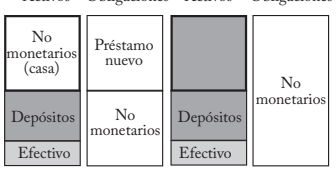

y usa sus nuevos depósitos para pagar al vendedor de la casa

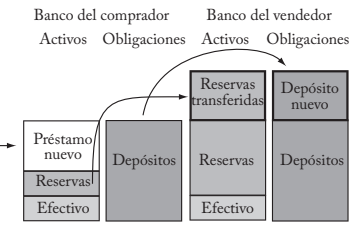

que son transferidos a el banco del vendedor, junto con las reservas, que el banco del comprador usa para compensar la transacción.

Pero compensar todas las transacciones de esta manera sería insostenible:

- El banco del comprador tendría menos reservas para satisfacer sus posibles desembolsos, por ejemplo, de retiros de depósitos. $-\mathrm{Y}$ si hicier.
sin reservas.

Banco del comprador Banco del vendedor

Activos Obligaciones Activos Obligaciones

Préstamo Depósto

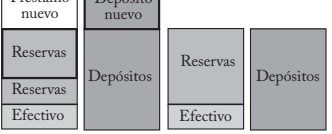

De modo que el banco del comprador en la práctica intentará atraer $o$ retener nuevos depositos (y reservas) - En el ejemplo que se muestra aquí, del banco del vendedor - para acompañar sus préstamos nuevos.

(a) Los balances son muy estilizados para facilitar la exposición: las cantidades de cada tipo de dinero que se muestra no corresponden a las cantidades que realmente se mantienen en el balance de cada sector.

préstamos. Cuando un banco hace un préstamo, la tasa de interés que cobra normalmente incluye una compensación por el nivel promedio de pérdidas de crédito que el banco espera sufrir. El tamaño de este componente de la tasa de interés será mayor cuando los bancos estiman que sufrirán pérdidas más altas, por ejemplo, cuando prestan a deudores hipotecarios con una alta relación préstamo-valor. Cuando los bancos amplían el crédito, es probable que aumente su pérdida esperada promedio por préstamo, lo que hace menos rentables esos préstamos. Esto limita aún más la cantidad de préstamos que pueden hacer en forma rentable y, por tanto, el dinero que pueden crear.

Las fuerzas del mercado no siempre llevan a que los bancos individuales se protejan suficientemente contra los riesgos de liquidez y de crédito. Por ello, la regulación prudencial busca asegurar que no tomen riesgos excesivos cuando hacen préstamos nuevos, incluso mediante requerimientos de capital y de posiciones de liquidez. Estos 
requerimientos pueden actuar entonces como un freno adicional a la cantidad de dinero que los bancos comerciales crean haciendo préstamos. El marco de la regulación prudencial, junto con más detalles sobre el capital y la liquidez, se describe en Farag et al. (2013).

Hasta ahora, esta sección ha considerado el caso de un banco individual que hace préstamos adicionales ofreciendo tasas de interés competitivas sobre sus préstamos y depósitos. Pero si todos los bancos deciden simultáneamente tratar de hacer más préstamos, el crecimiento del dinero no se puede limitar de la misma manera. Aunque un banco individual pueda perder depósitos con otros bancos, igualmente podría ganar algunos depósitos como resultado de los préstamos que hacen otros bancos.

Hay numerosas razones para que muchos bancos elijan aumentar notablemente sus préstamos al mismo tiempo. Por ejemplo, la rentabilidad del crédito a tasas de interés dadas puede aumentar debido a una mejora general de las condiciones económicas. Así mismo, los bancos pueden decidir prestar más si perciben que han disminuido los riesgos asociados a la concesión de préstamos a los hogares y compañías. A veces se argumenta que este tipo de desarrollo es una de las razones por las que se amplió tanto el crédito bancario en el periodo anterior a la crisis financiera ${ }^{16}$. Pero si esa percepción de un entorno menos riesgoso fuera injustificada, el resultado podría ser un sistema financiero más frágil ${ }^{17}$. En el Reino Unido, una de las respuestas a la crisis ha sido la creación de una autoridad macroprudencial, el Comité de Política Monetaria (CPM), para identificar, supervisar y tomar medidas para reducir o suprimir riesgos que amenacen la resiliencia del sistema financiero como un todo ${ }^{18}$.

\section{RESTRICCIONES QUE SURGEN DE LA RESPUESTA DE LOS HOGARES Y LAS COMPAÑÍAS}

Además del conjunto de restricciones que limitan la creación de dinero por los bancos, también puede ser importante el comportamiento de los hogares y las compañías en respuesta a la creación de dinero por el sector bancario, como argumenta Tobin. El comportamiento del sector privado no bancario influye en el impacto último de la creación de crédito por el sector bancario sobre la cantidad de dinero porque se puede crear más (o menos) dinero del que este sector desea mantener

${ }^{16}$ Ver, por ejemplo, Haldane (2009).

${ }_{17}$ Tucker (2009) analiza la posibilidad de tal "ilusión de riesgo" en el sistema financiero.

${ }_{18}$ Tucker et al. (2013) describen las nuevas facultades de diseño de políticas macroprudenciales en el Reino Unido a raíz de la reciente crisis financiera. 
en relación con otros activos (como propiedades o acciones). Como los hogares y las compañías que toman préstamos lo hacen porque desean gastar más, pasarán rápidamente ese dinero a otros cuando lo gastan. La respuesta de esos hogares y compañías determinará entonces la cantidad de dinero en la economía, y tiene implicaciones potenciales para el gasto y la inflación.

Hay dos principales posibilidades respecto de lo que podría ocurrir a los depósitos recién creados. La primera, como sugirió Tobin, que el dinero se destruya rápidamente si los hogares o compañías que lo reciben después de que se gasta el préstamo desean usarlo para pagar sus préstamos pendientes con los bancos. Esto a veces se denomina "teoría del reflujo"19. Por ejemplo, quien compra vivienda por primera vez puede hacer una hipoteca para comprar una casa a una persona mayor que, a su vez, paga su hipoteca pendiente y va a vivir con su familia. Como se comentó antes, el pago de préstamos bancarios destruye dinero así como la concesión de préstamos lo crea. Por ello, en este caso el balance de los consumidores retornaría a la posición en la que estaba antes de conceder el préstamo.

La segunda posibilidad es que la creación de dinero adicional por los bancos pueda llevar a un mayor gasto en la economía. Para que el dinero recién creado se destruya debe pasar a hogares y compañías que tienen préstamos pendientes y desean pagarlos. Pero este no siempre será el caso, pues las tenencias de activos y deudas tienden a variar notablemente entre individuo ${ }^{20}$. En cambio, el dinero puede pasar inicialmente a hogares o compañías con tenencias positivas de activos financieros: la persona mayor ya puede haber cancelado su hipoteca, o una compañía que recibe dinero como pago ya puede tener activos líquidos suficientes para cubrir posibles desembolsos. Pueden quedarse entonces manteniendo más dinero del que desean, e intentan reducir su "exceso" de tenencias de dinero aumentando su gasto en bienes y servicios. (En el caso de una compañía puede en cambio comprar otros activos de mayor rendimiento.)

Estos dos escenarios de lo que le ocurre al dinero recién creado -ser destruido rápidamente o circular a través del gasto- tienen implicaciones muy diferentes para la actividad económica. En el segundo, el dinero puede seguir pasando entre diferentes hogares y compañías que, a su vez, pueden aumentar su gasto. Este proceso - a veces llamado efecto de "papa caliente"- puede llevar, si lo demás sigue igual, a un

19 Ver Kaldor y Trevithick (1981).

${ }^{20}$ Ver Kamath et al. (2011). 
aumento de la presión inflacionaria en la economía ${ }^{21}$. En cambio, si el dinero se destruye rápidamente como en el primer escenario, no habrá necesariamente efectos adicionales sobre la economía.

Esta sección hasta ahora ha analizado cómo pueden afectar las acciones de bancos, hogares y compañías la cantidad de dinero en la economía y por tanto, la presión inflacionaria. Pero el determinante último de las condiciones monetarias de la economía es la política monetaria del banco central.

\section{POLÍTICA MONETARIA - LA RESTRICCIÓN ÚLTIMA A LA CREACIÓN DE DINERO}

Uno de los principales objetivos del Banco de Inglaterra es asegurar la estabilidad monetaria manteniendo la inflación de precios al consumidor en la línea de cumplir la meta del $2 \%$ fijada por el gobierno. Y, como se mostró en el recuadro de las páginas 9-10, durante algunos periodos de tiempo, las diversas medidas del dinero han crecido a una tasa similar a la del gasto nominal, la cual determina la presión inflacionaria en la economía en el mediano plazo. De modo que establecer apropiadamente la política monetaria para cumplir la meta de inflación debería asegurar en últimas una tasa estable de creación de crédito y de dinero consistente con el cumplimiento de esa meta. Esta sección explica la relación entre política monetaria y diferentes tipos de dinero.

En tiempos normales, el CPM, igual que la mayoría de sus equivalentes en otros países, implementa la política monetaria fijando tasas de interés de corto plazo, específicamente fijando la tasa de interés que se paga por las reservas que los bancos comerciales mantienen en el banco central. Y puede hacerlo por la posición del Banco como proveedor monopólico de dinero del banco central en el Reino Unido. Y es debido a que hay demanda de dinero del banco central -el medio último de compensación para los bancos, los creadores de dinero en sentido amplio- que el precio de las reservas tiene un impacto significativo sobre otras tasas de interés de la economía.

La tasa de interés que pueden obtener los bancos comerciales por el dinero colocado en el banco central influye en la tasa a la que están dispuestos a prestar en términos similares en los mercados de dinero; los mercados en los que el Banco y los bancos comerciales se prestan entre sí y a otras instituciones financieras. Los detalles exactos del modo en que el Banco usa sus operaciones en el mercado de dinero

\footnotetext{
${ }^{21}$ Este mecanismo se explica en más detalle en Laidler (1984), Congdon (1992, 2005), Howells (1995), Laidler y Robson (1995), Bridges et al. (2011) y Bridges y Thomas (2012).
}

Revista de Economía Institucional, vol. i7, n.o 33, segundo semestre/20i5, pp. 355-383 
para implementar la política monetaria han variado a través del tiempo, y los procedimientos operativos actuales del banco central difieren entre países, como se discute en Clews et al. (2010) ${ }^{22}$. Las variaciones de las tasas de interés interbancarias operan, a su vez, a través de un conjunto más amplio de tasas de interés en los diferentes mercados y a plazos diferentes, incluidas las tasas de interés que los bancos cobran a los prestatarios por los préstamos y ofrecen a los ahorradores por los depósitos ${ }^{23}$. Influyendo en el precio del crédito de este modo, la política monetaria afecta la creación de dinero en sentido amplio.

Esta descripción de la relación entre política monetaria y dinero difiere de la descripción de muchos manuales introductorios, donde los bancos centrales determinan la cantidad de dinero en sentido amplio a través de un "multiplicador monetario" variando activamente la exigencia de reservas ${ }^{24}$. Según esa concepción, los bancos centrales implementan la política monetaria eligiendo la cantidad de reservas. $Y$, debido a que se supone una relación estable entre dinero en sentido amplio y base monetaria, estas reservas se "multiplican" mediante una variación mucho mayor de los depósitos bancarios cuando los bancos incrementan los préstamos y depósitos.

Ningún paso de esa historia es una descripción exacta de la relación entre dinero y política monetaria en la economía moderna. Los bancos centrales normalmente no eligen una cantidad de reservas para lograr la tasa de interés de corto plazo deseada $a^{25}$. En cambio, se centran en los precios, fijando tasas de interés ${ }^{26}$. E1 Banco de Inglaterra controla las tasas de interés suministrando y remunerando las reservas a la tasa política escogida. E1 suministro de reservas y efectivo (que en conjunto forman la base monetaria) es determinado por la demanda de reservas de los bancos para compensar pagos y para satisfacer la demanda de efectivo de sus clientes; demanda que el banco central normalmente satisface.

Es entonces más probable que esta demanda de base monetaria sea una consecuencia y no una causa de que los bancos hagan préstamos y creen dinero en sentido amplio. Porque las decisiones de los bancos

${ }^{22}$ El marco para las operaciones del Banco en los mercados de dinero se establece en el "Libro Rojo" del Banco, disponible en [www.bankofengland.co.uk/ markets/Documents/money/publications/redbook.pdf]. Los desarrollos recientes en los mercados de dinero se analizan en Jackson y Sim (2013).

${ }^{23}$ Bank of England (1999) analiza en más detalle el mecanismo de transmisión de la política monetaria.

${ }^{24}$ Benes y Kumhof (2012) discuten en más detalle el mito del multiplicador monetario.

${ }^{25}$ Como se analiza en Disyatat (2008).

${ }^{26}$ Bindseil (2004) explica en detalle cómo funciona la implementación de la política monetaria a través de las tasas de interés de corto plazo. 
de conceder crédito se basan en la disponibilidad de oportunidades de préstamo rentables en cualquier momento. La rentabilidad de hacer préstamos depende de muchos factores, como ya se comentó. Uno de ellos, el costo de los fondos que enfrentan los bancos, que está relacionado estrechamente con la tasa de interés que se paga sobre las reservas, la tasa de política.

En contraste, la cantidad de reservas que están en el sistema no limita la creación de dinero en sentido amplio a través del acto de hacer préstamos ${ }^{27}$. Este aspecto del multiplicador monetario a veces se justifica apelando a los requerimientos de reservas del banco central, que obligan a los bancos a mantener una cantidad mínima de reservas igual a una proporción fija de sus tenencias de depósitos. Pero los requerimientos de reservas no son hoy un aspecto importante de los marcos de política monetaria en la mayoría de las economías avanzadas $^{28}$.

Es probable que una postura de política monetaria más laxa aumente la cantidad de dinero en sentido amplio reduciendo las tasas de préstamos y aumentando el volumen de préstamos. Y una mayor cantidad de dinero en sentido amplio, acompañada de un aumento del nivel de gasto en la economía, puede dar lugar a que los bancos y los clientes demanden más reservas y efectivo ${ }^{29}$. Así, la teoría del multiplicador monetario funciona en realidad en forma opuesta a la que se describe normalmente.

\section{FC - CREACIÓN DIRECTA DE DINERO EN SENTIDO AMPLIO CON LA POLÍTICA MONETARIA}

La sección anterior comentó por qué la política monetaria se puede ver como límite último a la creación de dinero por los bancos comerciales. Pero los bancos comerciales pueden crear alternativamente una cantidad de dinero demasiado pequeña para que sea consistente con el cumplimiento de la meta de inflación. En tiempos normales, el

${ }^{27}$ Carpenter y Demiralp (2012) muestran que las variaciones de la cantidad de reservas no están relacionadas con las variaciones de la cantidad de préstamos en Estados Unidos.

${ }_{28}$ Actualmente, el Banco de Inglaterra no hace requerimientos formales de reservas, por ejemplo. (Requiere que los bancos mantengan en el Banco una proporción de la "relación efectivo a depósitos" sin intereses para un subconjunto de sus obligaciones. Pero la función de esta relación efectivo a depósitos no es operativa. Su único propósito es proporcionar ingresos al Banco.) Bernanke (2007) analiza por qué los requerimientos de reservas no son hoy una restricción como en el pasado en Estados Unidos.

29 Kydland y Prescott (1990) encontraron que los agregados de dinero en sentido amplio impulsaron el ciclo, mientras que los agregados de la base monetaria tendieron a retrasar ligeramente el ciclo. 
CPM puede responder reduciendo la tasa política para promover más préstamos y, por tanto, más creación de dinero. Pero, en respuesta a la crisis económica, el CPM redujo la tasa bancaria al 0,5\%, el llamado límite efectivo inferior.

Una vez las tasas de interés de corto plazo llegan al límite efectivo inferior, no es posible que el banco central proporcione más estímulo a la economía reduciendo la tasa a la que se remuneran las reservas ${ }^{30}$. Una manera posible de proporcionar estímulo monetario adicional a la economía es recurrir a un programa de compra de activos (FC). Igual que las reducciones de las tasa del Banco, las compras de activos son un medio por el cual el CPM puede relajar la posición de política monetaria para estimular la actividad económica y cumplir su meta de inflación. Pero el papel del dinero en las dos políticas no es el mismo.

La FC desplaza el enfoque de política monetaria a la cantidad de dinero: el banco central compra una cantidad de activos, financiados por la creación de dinero en sentido amplio y un incremento correspondiente en la cantidad de reservas en el banco central. Los vendedores de activos se quedarán con los depósitos recién creados en vez de bonos del gobierno. Es probable que mantengan más dinero del que querrían, con respecto a otros activos que quieran mantener. Por ello querrán rebalancear sus portafolios, por ejemplo, usando los depósitos nuevos para comprar activos de mayor rendimiento, como bonos y acciones emitidas por las empresas, lo que provoca el efecto "papa caliente" ya mencionado. Esto elevará el valor de esos activos y reducirá el costo para las empresas de recaudar fondos en estos mercados. Eso, a su vez, debe llevar a un mayor gasto en la economía ${ }^{31}$. $\mathrm{E} 1$ modo en que funciona la $\mathrm{FC}$ difiere entonces de dos concepciones erróneas comunes de las compras de activos del banco central: que la FC implica dar "dinero gratuito" a los bancos y que el objetivo clave de la FC es aumentar el crédito bancario proporcionando más reservas al sistema bancario, como lo describiría la teoría del multiplicador monetario. Esta sección explica la relación entre dinero y FC y disipa estas concepciones erróneas.

${ }^{30} \mathrm{Si}$ el banco central redujera las tasas de interés significativamente por debajo de cero, los bancos podrían cambiar sus reservas bancarias por efectivo, el cual pagaría una tasa de interés más alta (de cero o ligeramente inferior después de tener en cuenta los costos de almacenar efectivo). O, dicho de otra manera, la demanda de reservas del banco central desaparecería, de modo que el banco central ya no podría influir en la economía variando el precio de esas reservas.

${ }^{31}$ Las formas en que la FC afecta la economía se cubren en más detalle en Benford et al. (2009), Joyce et al. (2011) y Bowdler y Radia (2012). El papel de dinero más específicamente se describe en Bridges et al. (2011), Bridges y Thomas (2012) y Butt et al. (2012). 


\section{El contenido de información de los diferentes tipos de dinero $y$ de agregados monetarios}

Uno de los principales objetivos del Banco de Inglaterra es asegurar la estabilidad monetaria manteniendo la inflación en el camino de cumplir la meta del gobierno del 2\%. Milton Friedman (1963) argumentó que "la inflación es siempre y en todas partes un fenómeno monetario". De modo que las variaciones de la oferta monetaria pueden contener valiosa información sobre el gasto y la presión inflacionaria en la economía. Puesto que el dinero es esencial para comprar bienes y servicios, es probable que contenga información corroborativa del nivel actual de gasto nominal en la economía. También puede proporcionar información incremental de los movimientos futuros del gasto nominal, y puede ser entonces un indicador útil de la presión inflacionaria futura. Por último, el comportamiento del dinero puede ayudar a revelar la naturaleza del mecanismo de transmisión monetaria, en especial cuando la política monetaria opera a través de la "flexibilización cuantitativa" (FC).

En la práctica, una dificultad clave es decidir qué medidas del dinero es apropiado observar para cada uno de los diferentes propósitos. El Banco actualmente construye varios agregados monetarios y publica un conjunto de datos que se pueden crear y se sintetizan en el cuadro 1R. La gráfica A muestra algunas series de tiempo históricas de largo plazo del crecimiento de los agregados monetarios comparadas con las del gasto nominal ${ }^{1}$. Dados los diversos cambios en el régimen monetario del Reino Unido durante los últimos 150 años, es improbable que un solo indicador monetario capte perfectamente la información corroborativa e incremental del dinero. El sector financiero del Reino Unido también ha experimentado diversos cambios estructurales que se deben tener en cuenta cuando se considera el vínculo subyacente entre dinero y gasto. Por ejemplo, durante periodos en que el sector financiero ha crecido con respecto al resto de la economía (como a comienzos de las décadas de 1980 y 2000), el dinero en sentido amplio ha tendido a crecer persistentemente más rápido que el gasto nominal.

Las medidas más estrechas del dinero, como billetes y monedas y depósitos a la vista (cuentas que se pueden retirar inmediatamente sin sanción) son, en principio, mejores indicadores corroborativos del gasto, pues es probable que sean los tipos de dinero que se usan para realizar la mayoría de las transacciones de bienes y servicios. La suma de billetes y monedas y de depósitos a la vista que mantiene el sector privado no bancario a veces se conoce como dinero de madurez cero o "DMC"

Las medidas más amplias del dinero pueden ser más apropiadas como indicadores incrementales del gasto futuro y más reveladoras de la naturaleza del mecanismo de transmisión. M2, por ejemplo, incluye además depósitos temporales de los hogares como las cuentas de ahorros ${ }^{3}$. Y M4 es una medida aún más amplia que incluye todos los depósitos temporales y a la vista que mantienen las compañías no financieras y las compañías financieras no bancarias. El texto principal describe cómo funciona la FC, aumentando primero los depósitos de las compañías financieras. Cuando estas compañías rebalancean sus portafolios, es probable que los precios de los activos aumenten y que, con un rezago, lleven a un incremento del gasto de los hogares y compañías. Por ello el monitoreo del dinero en sentido amplio ha sido una parte importante de la evaluación de la efectividad de la $\mathrm{FC}^{4}$.

Numerosos estudios econométricos sugieren que los movimientos sectoriales del dinero en sentido amplio también pueden proporcionar valiosa información incremental del gasto en la economía ${ }^{5}$. Por ejemplo, los depósitos de las 
compañías no financieras parecen ser un indicador anticipado de la inversión empresarial. También se pueden probar y ponderar diferentes tipos de dinero estrecho y amplio usando una métrica de la cantidad de cada tipo de dinero que se usa en las transacciones, conocida como índice Divisia ${ }^{6}$. En la práctica, como métrica de ponderación normalmente se usan los intereses que se pagan sobre un tipo dado de dinero. Porque es probable que los individuos y compañías solo mantengan dinero que gana una tasa de interés baja con respecto a otros instrumentos financieros si los compensa proporcionándoles mayores servicios de transacciones.

La identificación de la medida apropiada del dinero se ha complicado debido al continuo desarrollo del sector financiero. Esto ha ampliado la gama de instrumentos que pueden servir como dinero y de instituciones financieras que se endeudan $y$ depositan en el sistema bancario tradicional. Por ejemplo, los acuerdos de venta y recompra (conocidos como repos) -en los que una empresa acuerda comprar un título a un banco con el acuerdo de revendérselo después- actualmente se incluyen en M4 porque la obligación de recompra se puede considerar como un depósito asegurado.

Además, algunos economistas argumentan que un conjunto de instrumentos que garantizan diversos tipos de deudas y créditos también se pueden incluir en una medida más amplia del dinero ${ }^{7}$. Por otra parte, muchas de las entidades no bancarias que mantienen depósitos son principalmente intermediarias entre los bancos. Es probable que los depósitos de estas entidades, conocidas como "otras corporaciones financieras intermediarias” (OCFI), reflejen actividades internas al sistema bancario no relacionadas directamente con el gasto en la economía ${ }^{8}$. Por esta razón, la medida más usual del dinero en sentido amplio del Banco es $\mathrm{M}^{\mathrm{ex}}{ }^{\text {, }}$ que excluye depósitos OCFI.

\section{Cuadro $1 \mathrm{R}$}

Agregados monetarios populares que se pueden construir con los datos disponibles del Reino Unido ${ }^{(a)}$

\begin{tabular}{|c|c|c|c|}
\hline Nombre & Definición & Descripción $^{(\mathrm{b})}$ & Disponibilidad \\
\hline Billetes y monedas & $\begin{array}{l}\text { Billetes y monedas en } \\
\text { circulación fuera del Banco } \\
\text { de Inglaterra }\end{array}$ & $\begin{array}{l}\text { La medida más estrecha del dinero y } \\
\text { usada como indicador de las transac- } \\
\text { ciones en efectivo }\end{array}$ & 1870-presente ${ }^{(\mathrm{c})}$ \\
\hline$\overline{\mathrm{MO}}$ & $\begin{array}{l}\text { Billetes y monedas más } \\
\text { reservas en el banco central }\end{array}$ & $\begin{array}{l}\text { La medida básica del dinero usada } \\
\text { históricamente en los cálculos de } \\
\text { multiplicador monetario. A menudo } \\
\text { se usa como medida aproximada del } \\
\text { tamaño del balance del Banco de } \\
\text { Inglaterra } \\
\text { El Banco de Inglaterra ya no la publica } \\
\text { pero se puede reconstruir }{ }^{(d)}\end{array}$ & 1870-presente ${ }^{(c)}$ \\
\hline M1 sin intereses & $\begin{array}{l}\text { Billetes y monedas más } \\
\text { depósitos a la vista sin inte- } \\
\text { reses que mantiene el sector } \\
\text { privado no bancario }\end{array}$ & $\begin{array}{l}\text { Un indicador de las transacciones } \\
\text { de bienes y servicios en la economía; } \\
\text { hoy menos útil porque la mayoría de } \\
\text { los depósitos a la vista pagan alguna } \\
\text { forma de interés } \\
\text { El Banco de Inglaterra no lo publica } \\
\text { pero se puede construir a partir de los } \\
\text { componentes publicados }\end{array}$ & 1921-presente ${ }^{(c)}$ \\
\hline$\overline{\mathrm{DMC}}$ & $\begin{array}{l}\text { Billetes y monedas más } \\
\text { depósitos a la vista que } \\
\text { mantiene el sector privado } \\
\text { no bancario }\end{array}$ & $\begin{array}{l}\text { Un indicador de las transacciones de } \\
\text { bienes y servicios en la economía } \\
\text { El Banco de Inglaterra no lo publica } \\
\text { pero se puede construir a partir de } \\
\text { los componentes publicados El Banco } \\
\text { también produce una medida basada en } \\
\text { una definición de M1 del BCE }\end{array}$ & 1977-presente \\
\hline
\end{tabular}




\begin{tabular}{|c|c|c|c|}
\hline $\begin{array}{l}\text { M2 o M4 mino- } \\
\text { rista }\end{array}$ & $\begin{array}{l}\text { Billetes y monedas más to- } \\
\text { dos los depósitos minoristas } \\
\text { (incluidos los depósitos } \\
\text { minoristas temporales) que } \\
\text { mantiene el sector privado } \\
\text { no bancario }\end{array}$ & $\begin{array}{l}\text { Una medida del dinero más amplia } \\
\text { que DMC que abarca todos los } \\
\text { depósitos minoristas. Las adiciones } \\
\text { clave son los depósitos temporales } \\
\text { de los hogares y algunos depósitos } \\
\text { temporales minoristas corporativos } \\
\text { El Banco también produce una medida } \\
\text { basada en una definición de } M 2 \text { del } \\
\text { BCE }\end{array}$ & 1982-presente \\
\hline M3 & $\begin{array}{l}\text { Billetes y monedas más to- } \\
\text { dos los depósitos temporales } \\
\text { y a la vista que mantiene el } \\
\text { sector privado no bancario } \\
\text { en los bancos (excepto en las } \\
\text { sociedades de construcción) }\end{array}$ & $\begin{array}{l}\text { Hasta } 1987 \text { fue el principal agregado } \\
\text { monetario construido por el Banco } \\
\text { de Inglaterra } \\
\text { El Banco también produce una medida } \\
\text { basada en una definición de M3 del } \\
\text { BCE }\end{array}$ & $1870-1990^{(\mathrm{c})}$ \\
\hline M4 & $\begin{array}{l}\text { Billetes y monedas, depó- } \\
\text { sitos, certificados de depó- } \\
\text { sito, repos y títulos con una } \\
\text { madurez menor de cinco } \\
\text { años que mantiene el sector } \\
\text { privado no bancario }\end{array}$ & $\begin{array}{l}\text { Hasta } 2007 \text { fue el principal agregado } \\
\text { monetario amplio construido por el } \\
\text { Banco de Inglaterra }\end{array}$ & 1963-presente \\
\hline$M 4^{\mathrm{ex}}$ & $\begin{array}{l}\text { M4 excluidos los depósitos } \\
\text { OCFI }\end{array}$ & $\begin{array}{l}\text { Desde } 2007 \text { es el principal agregado } \\
\text { monetario amplio construido por el } \\
\text { Banco de Inglaterra }\end{array}$ & 1997-presente \\
\hline Divisia & $\begin{array}{l}\text { Una suma ponderada de los } \\
\text { diferentes tipos de dinero }\end{array}$ & $\begin{array}{l}\text { Busca ponderar los activos compo- } \\
\text { nentes del dinero en sentido amplio } \\
\text { de acuerdo con los servicios de } \\
\text { transacciones que proporcionan } \\
\text { (e) }\end{array}$ & 1977-presente \\
\hline
\end{tabular}

(a) Todas las definiciones se refieren únicamente a instrumentos en libras esterlinas. Algunas de las definiciones de este cuadro se modificaron en diversos momentos. Por ejemplo, el agregado original M3 incluía depósitos del sector público y las tenencias de depósitos en moneda extranjera del sector privado no bancario. Una historia más exhaustiva del desarrollo de los agregados monetarios del Reino Unido se puede encontrar en [www.bankofengland.co.uk/statistics/Documents/ms/articles/art2jul03.pdf].

(b) Publicado por el Banco de Inglaterra a menos que se indique lo contrario.

(c) Esta serie usa los datos construidos por Capie y Webber (1985).

(d)Los datos de $\mathrm{M} 0$ se descontinuaron después de las reformas a las operaciones del mercado de dinero del Banco de Inglaterra en 2006. Ver [www.bankofengland.co.uk/statistics/Documents/ms/articles/artjun06.pdf].

(e) Los índices Divisia para otras corporaciones financieras y para el sector privado no bancario se descontinuaron en 2013. Para más detalles, ver [www.bankofengland.co.uk/statistics/Documents/ms/articles/art1aug13.pdf].

${ }^{1}$ Estas series involucran un empalme de los datos actuales del Banco de Inglaterra con datos históricos de los agregados monetarios.

${ }^{2}$ También se puede construir una medida más estrecha conocida como M1 sin intereses. Esta medida se ha convertido en un agregado menos útil porque la mayoría de los depósitos a la vista hoy pagan alguna forma de interés. Por ejemplo, durante la crisis financiera cuando las tasas de interés cayeron a cerca de cero, el crecimiento de M1 sin intereses aumentó notablemente cuando el costo de mantener tenencias de depósitos sin intereses cayó fuertemente en comparación con los que reciben intereses. Enfocarse en M1 habría dado una señal engañosa del crecimiento del gasto nominal en la economía.

${ }^{3} \mathrm{M} 2$ incluye tenencias de billetes y monedas del sector privado no bancario más depósitos “minoristas”, que son depósitos que pagan una tasa de interés anunciada. Esos son en su mayoría depósitos de los hogares pero también se aplican a algunos depósitos corporativos.

${ }^{4}$ Ver Bridges et al. (2011) y Butt et al. (2012).

${ }^{5}$ Ver, p. ej., Astley y Haldane (1995), Thomas (1997a, b) y Brigden y Mizen (2004).

${ }^{6}$ Ver, p. ej., Hancock (2005).

${ }^{7}$ Ver, p. ej., Singh (2013).

${ }^{8}$ Ver Burgess y Janssen (2007) y para más detalles www.bankofengland.co.uk/statistics/Pp./iadb/notesiadb/ m4adjusted.aspx 


\section{EL VÍNCULO ENTRE LA FC Y LAS CANTIDADES DE DINERO}

La FC tiene un efecto directo sobre las cantidades de base monetaria y de dinero amplio debido al modo en que el Banco realiza sus compras de activos. La política busca comprar activos, bonos del gobierno, principalmente a compañías financieras no bancarias, como los fondos de pensiones o las compañías de seguros. Consideremos, por ejemplo, la compra de mil millones de libras en bonos del gobierno a un fondo de pensiones. Una manera de realizar la compra sería que el Banco imprimiera mil millones de libras en billetes y los intercambiara directamente con el fondo de pensiones. Pero la transacción de billetes en tan grandes cantidades no es práctica. Este tipo de transacciones se realiza, por tanto, usando formas electrónicas de dinero.

Gráfica 3

Impacto de la FC en los balances ${ }^{(a)}$

Antes de la compra de activos Después de la compra de activos
Fondo de pensiones
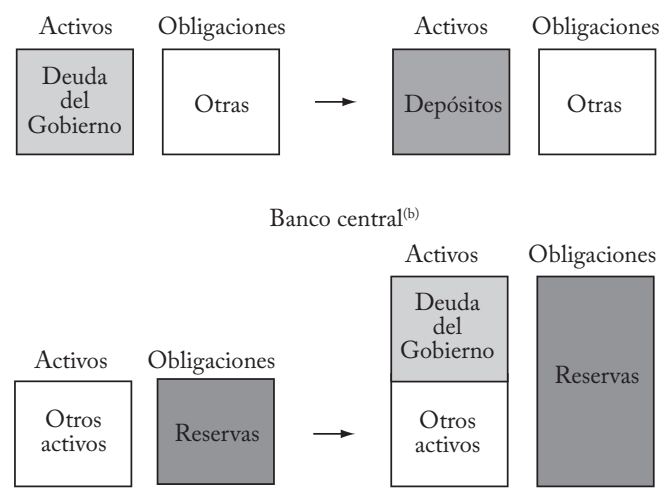

Banco comercial

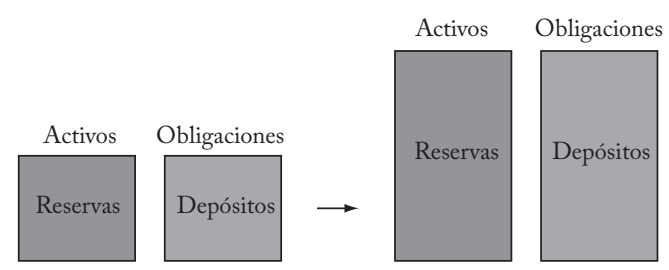

(a) Los balances son sumamente estilizados para facilitar la exposición: las cantidades de activos y obligaciones que se muestran no corresponden a las cantidades que mantienen realmente estos sectores. La gráfica solo muestra activos y obligaciones relevantes para la transacción.

(b) La deuda del gobierno es realmente comprada por el Programa de Compras de Activos del Banco de Inglaterra usando un préstamo del Banco de Inglaterra, de modo que no aparece directamente en el balance consolidado oficial del Banco. 
Como el fondo de pensiones no mantiene una cuenta de reservas en el Banco de Inglaterra, se usa como intermediario al banco comercial en el que tiene una cuenta bancaria. El banco del fondo de pensiones acredita mil millones de libras de depósitos en la cuenta del fondo de pensiones a cambio de los bonos del gobierno. Esto se muestra en el primer panel de la gráfica 3. E1 Banco de Inglaterra financia su compra acreditando reservas en la cuenta del banco del fondo de pensiones; le da un pagaré al banco comercial (segunda fila). El balance del banco comercial se amplía: las obligaciones de depósitos nuevos se emparejan con un activo en forma de reservas nuevas (tercera fila).

\section{DOSCONCEPCIONESERRÓNEASACERCADELFUNCIONAMIENTO DE LA FC}

\section{POR QUÉ LAS RESERVAS ADICIONALES NO SON “DINERO GRATUITO” PARA LOS BANCOS}

Mientras que las compras de activos del banco central involucran -y afectan- los balances de los bancos comerciales, el papel principal de esos bancos es el de intermediarios que facilitan la transacción entre el banco central y el fondo de pensiones. Las reservas adicionales que se muestran en la gráfica 3 son simplemente un subproducto de esta transacción. A veces se argumenta que, debido a que son activos que mantienen los bancos comerciales y ganan intereses, estas reservas son "dinero gratuito" para los bancos. Aunque los bancos ganan intereses sobre las reservas recién creadas, la FC también crea una obligación acompañante del banco en forma de depósito del fondo de pensiones, sobre la que el mismo banco normalmente tendrá que pagar intereses. En otras palabras, la FC deja a los bancos con un pagaré nuevo del banco central y también con un pagaré nuevo, de igual monto, $a$ los consumidores (en este caso, el fondo de pensiones), y las tasas de interés de ambos dependen de la tasa del banco central.

\section{POR QUÉ LAS RESERVAS ADICIONALES NO SE MULTIPLICAN EN NUEVOS PRÉS- TAMOS Y DINERO EN SENTIDO AMPLIO}

Como ya se señaló, el mecanismo de transmisión de la FC se basa en los efectos del dinero en sentido amplio recién creado, y no en los de la base monetaria. El inicio de esa transmisión es la creación de depósitos bancarios en el balance del tenedor de activos en el lugar de la deuda del gobierno (gráfica 3, primera fila). Es importante señalar que las reservas creadas en el sector bancario (gráfica 3, tercera fila) no juegan un papel central. Porque, como se explicó antes, los bancos 
no pueden prestar reservas directamente. Las reservas son un pagaré del banco central a los bancos comerciales. Esos bancos las pueden usar para hacer sus pagos mutuos, pero no las pueden "prestar" a los consumidores, quienes no mantienen cuentas de reservas en el banco central. Cuando los bancos hacen préstamos adicionales estos se compensan con depósitos adicionales; y la cantidad de reservas no cambia.

Además, las nuevas reservas no se multiplican mecánicamente en préstamos y depósitos nuevos como predice la teoría del multiplicador monetario. La FC aumenta el dinero en sentido amplio sin provocar directamente, o requerir, un aumento del crédito. Mientras que la primera etapa de la teoría del multiplicador monetario se mantiene durante la FC -la posición monetaria determina mecánicamente la cantidad de reservas-, las reservas recién creadas, por sí mismas, no alteran significativamente los incentivos para que los bancos creen nuevo dinero en sentido amplio haciendo préstamos. Es posible que la FC pueda afectar indirectamente los incentivos que enfrentan los bancos para hacer préstamos nuevos, por ejemplo, reduciendo sus costos de financiación o aumentando el volumen de crédito fomentando la actividad ${ }^{32}$. Pero igualmente, la FC podría llevar a que las compañías paguen el crédito bancario, si emitieran más bonos o acciones y usaran esos fondos para pagar los préstamos bancarios. En suma, es por tanto posible que la FC aumente o reduzca la cantidad de crédito bancario en la economía. Sin embargo, no se espera que estos canales sean parte clave de su transmisión: en cambio, la FC funciona eludiendo al sector bancario, en busca de aumentar directamente el gasto del sector privado ${ }^{33}$.

\section{CONCLUSIÓN}

Este artículo describe cómo se crea el dinero en la economía moderna. La mayor parte del dinero en circulación es creada, no por las imprentas del Banco de Inglaterra sino por los bancos comerciales: los bancos crean dinero cada vez que hacen un préstamo a cualquier participante en la economía o compran un activo a los consumidores. $\mathrm{Y}$ en contraste con las descripciones de algunos manuales, el Banco de Inglaterra no controla directamente la cantidad de dinero en sentido amplio ni la base monetaria. No obstante, el Banco de Inglaterra aún puede influir en la cantidad de dinero en la economía. En tiempos

${ }^{32}$ Un mecanismo similar por medio del cual la FC puede aumentar el crédito bancario permitiendo que los bancos atraigan más fondos estables se analiza en Miles (2012).

${ }^{33}$ Estos canales, junto con el efecto de la FC sobre el crédito bancario más en general, se discuten en detalle en un recuadro de Butt et al. (2012). 
normales influye estableciendo la política monetaria; a través de la tasa de interés que paga sobre las reservas que los bancos comerciales mantienen en el Banco de Inglaterra. Más recientemente, sin embargo, con una tasa bancaria restringida por el límite efectivo inferior, el programa de compras de activos del Banco de Inglaterra ha intentado aumentar la cantidad de dinero en sentido amplio en circulación. Esto a su vez afecta los precios y las cantidades de un conjunto de activos de la economía, incluido el dinero.

Diagrama A

Los diferentes agregados monetarios y el gasto nominal

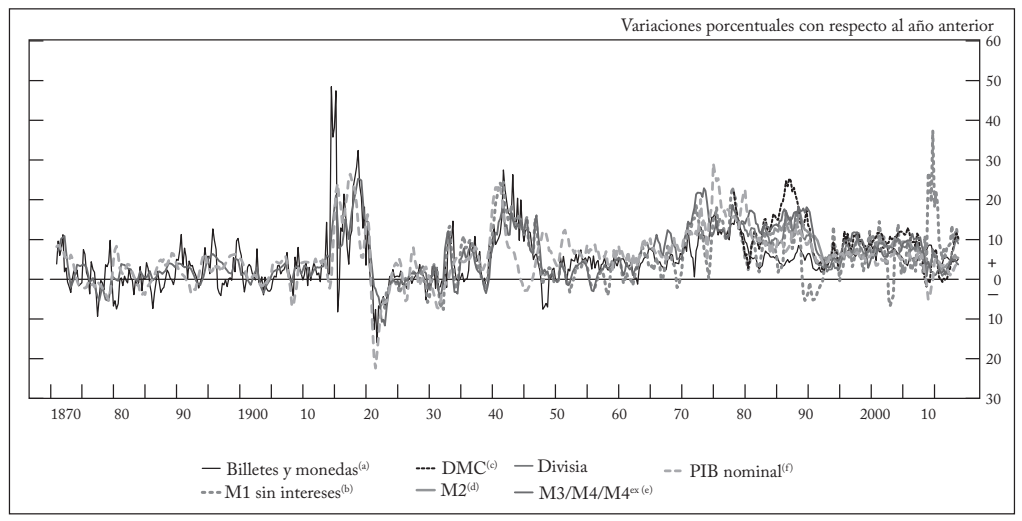

(a) 1969-II a 2013-IV: billetes y monedas en circulación. 1870-I a 1969-II: M0 de Capie y Webber (1985).

(b) 1977-I a 2013-IV: billetes y monedas que mantiene el sector privado no bancario y de sociedades de construcción más depósitos sin intereses. Antes de 2008-I, excluye depósitos en sociedades de construcción. 1963-I a 1977-I: datos históricos de M1 de los Quarterly Bulletins del Banco de Inglaterra. 1921-IV a 1963-I: Capie y Webber (1985).

(c) Billetes y monedas que mantiene el sector privado no bancario y de sociedades de construcción más depósitos totales a la vista. Antes de 1998-I excluye depósitos en sociedades de construcción.

(d) Billetes y monedas y depósitos al por menor que mantiene el sector privado no bancario y de sociedades de construcción.

(e) 1997-IV a 2013-IV: M4 excluyendo OCFI. 1963-I a 1997-IV: M4. 1870-II a 1963-I: M3 de Capie y Webber (1985).

(f) Estimación compuesta del PIB nominal a precios de mercado. Para los detalles, ver el apéndice de Hills et al. (2010).

Fuentes: Banco de Inglaterra, Capie y Webber (1985), Mitchell (1988), ONS, Sefton y Weale (1995), Solomou y Weale (1991); cálculos del Banco. Todas las series se ajustaron estacionalmente y por intervalos cuando fue posible. Los datos históricos se ajustaron estacionalmente usando X12.

\section{REFERENCIAS BIBLIOGRÁFICAS}

1. Astley, M. y A. Haldane. "Money as an indicator", Bank of England working paper No. 35, 1995. 
2. Bank of England. "The transmission mechanism of monetary policy”, 1999, [www.bankofengland.co.uk/publications/ Documents/other/ monetary/montrans.pdf].

3. Benes, J y M. Kumhof. “The Chicago Plan revisited”, IMF working paper No. 12/202, 2012.

4. Benford, J.; S. Berry, K. Nikolov, M. Robson y C. Young. "Quantitative easing”, Bank of England Quarterly Bulletin 49, 2, 2009, pp. 90-100.

5. Bernanke, B. "The financial accelerator and the credit channel", speech at a conference on The Credit Channel of Monetary Policy in the Twenty-first Century, Federal Reserve Bank of Atlanta, 2007.

6. Bindseil, U. "The operational target of monetary policy and the rise and fall of the reserve position doctrine", ECB working paper No. 372, 2004.

7. Bowdler, C. y A. Radia. "Unconventional monetary policy: the assessment", Oxford Review of Economic Policy 28, 4, 2012, pp. 603-621.

8. Bridges, J.; N. Rossiter y R. Thomas. "Understanding the recent weakness in broad money growth", Bank of England Quarterly Bulletin 51, 1, 2011, pp. 22-35.

9. Bridges, J. y R. Thomas. "The impact of FC on the UK economy Some supportive monetarist arithmetic", Bank of England working paper No. 442, 2012.

10. Brigden, A. y P. Mizen. "Money, credit and investment in the UK industrial and commercial companies sector", The Manchester School 72, 1, 2004, pp. 72-79.

11. Burgess, S. y N. Janssen. "Proposals to modify the measurement of broad money in the United Kingdom: A user consultation", Bank of England Quarterly Bulletin 47, 3, 2007, pp. 402-414.

12. Butt, N.; S. Domit, L. Kirkham, M. McLeay y R. Thomas. "What can the money data tell us about the impact of FC?", Bank of England Quarterly Bulletin 52, 4, 2012, pp. 321-131.

13. Button, R.; S. Pezzini y N. Rossiter. "Understanding the price of new lending to households", Bank of England Quarterly Bulletin 50, 3, 2010, pp. 172-182.

14. Capie, F. y A. Webber. A monetary history of the United Kingdom, 1870-1982, vol. 1, Routledge, 1985.

15. Carpenter, S. y S. Demiralp. "Money, reserves, and the transmission of monetary policy: Does the money multiplier exist?", Journal of Macroeconomics 34, 1, 2012, pp. 59-75.

16. Clews, R.; C. Salmon y O. Weeken. "The Bank's money market framework", Bank of England Quarterly Bulletin 50, 4, 2010, pp. 292-301.

17. Congdon, T. Reflections on monetarism, Oxford, Clarendon Press, 1992.

18. Congdon, T. "Money and asset prices in boom and bust", Institute of Economic Affairs, Hobart paper No. 152, 2005.

19. Disyatat, P., "Monetary policy implementation: misconceptions and their consequences”, BIS working paper No. 269, 2008.

20. Farag, M.; D. Harland y D. Nixon. "Bank capital and liquidity", Bank of England Quarterly Bulletin 53, 3, 2013, pp. 201-215.

21. Friedman, M. Inflation: Causes and consequences, Bombay y Nueva York, Asia Publishing House, 1963. 
22. Haldane, A. "Why banks failed the stress test", 2009, [www.bankofengland.co.uk/archive/documents/historicpubs/speeches/2009/ speech374.pdf].

23. Hancock, M. "Divisia money", Bank of England Quarterly Bulletin, primavera de 2005, pp. 39-46.

24. Hills, S.; R. Thomas y N. Dimsdale. "The UK recession in context What do three centuries of data tell us?", Bank of England Quarterly Bulletin 50, 4, 2010, pp. 277-291.

25. Howells, P. "The demand for endogenous money", Journal of Post Keynesian Economics 18, 1, 1995, pp. 89-106.

26. Jackson, C. y M. Sim. "Recent developments in the sterling overnight money market", Bank of England Quarterly Bulletin 53, 3, 2013, pp. 223-232.

27. Joyce, M.; M. Tong y R. Woods, “The United Kingdom's quantitative easing policy: Design, operation and impact", Bank of England Quarterly Bulletin 51, 3, 2011, pp. 200-212.

28. Kaldor, N. y J. Trevithick. "A Keynesian perspective on money", Lloyds Bank Review, enero de 1981, pp. 1-19.

29. Kamath, K.; K. Reinold, M. Nielsen y A. Radia. “The financial position of British households: Evidence from the 2011 NMG Consulting survey”, Bank of England Quarterly Bulletin 51, 4, 2011, pp. 305-318.

30. Kydland, F. y E. Prescott. "Business cycles: Real facts and a monetary myth", Federal Reserve Bank of Minneapolis Quarterly Review 14, 2, 1990, pp. 3-18.

31. Laidler, D. “The buffer stock notion in monetary economics", The Economic Journal 94, Supplement: Conference Papers, 1984, pp. 17-34.

32. Laidler, D. y W. Robson. "Endogenous buffer-stock money", Credit, interest rate spreads and the monetary policy transmission mechanism, Session 3, conference on The Transmission of Monetary Policy held at the Bank of Canada in November 1994, 1995,

33. Miles, D. "Asset prices, saving and the wider effects of monetary policy”, 2012, [www.bankofengland.co.uk/publications/Documents/ speeches/2012/speech549.pdf].

34. Mitchell, B. R. British historical statistics, Cambridge, Cambridge University Press, 1988.

35. Moore, B. Horizontalists and verticalists: The macroeconomics of credit money, Cambridge University Press, 1988.

36. Palley, T. Post Keynesian economics: Debt, distribution and the macro economy, Macmillan, 1996.

37. Sefton, J. y M. Weale. Reconciliation of national income and expenditure: Balanced estimates of national income for the United Kingdom, 19201990, Cambridge, Cambridge University Press, 1995.

38. Singh, M. "Collateral and monetary policy", IMF working paper No. 13/186, 2013.

39. Solomou, S. N. y M. Weale, "Balanced estimates of UK GDP 18701913”, Explorations in Economic History 28, 1, 1991, pp. 54-63.

40. Thomas, R. "The demand for M4: a sectoral analysis, Part 1 - the personal sector”, Bank of England working paper No. 61, 1997a. 
41. Thomas, R. "The demand for M4: A sectoral analysis, Part 2 - The corporate sector", Bank of England working paper No. 62, 1997b.

42. Tobin, J. "Commercial banks as creators of "money", Cowles Foundation discussion papers No. 159, 1963.

43. Tucker, P. “The debate on financial system resilience: Macroprudential instruments", 2009, [www.bankofengland.co.uk/archive/Documents/ historicpubs/speeches/2009/speech407.pdf].

44. Tucker, P.; S. Hall y A. Pattani. "Macroprudential policy at the Bank of England”, Bank of England Quarterly Bulletin 53, 3, 2013, pp. 192-200. 